Proc. Indian Acad. Sci. (Earth Planet. Sci.), Vol. 104, No. 2, June 1995, pp. 221-248.

(C) Printed in India.

\title{
MONTBLEX tower observations: Instrumentation, data acquisition and data quality
}

\author{
S RUDRA KUMAR*, S AMEENULLA and A PRABHU \\ Centre for Atmospheric Sciences, Indian Institute of Science, Bangalore 560012, India \\ * Now at Experimental Aerodynamics Division, National Aerospace Laboratories, Bangalore \\ 560017 , India
}

\begin{abstract}
Tower platforms, with instrumentation at six levels above the surface to a height of $30 \mathrm{~m}$, were used to record various atmospheric parameters in the surface layer. Sensors for measuring both mean and fluctuating quantities were used, with the majority of them indigenously built. Soil temperature sensors up to a depth of $30 \mathrm{~cm}$ from the surface were among the variables connected to the mean data logger. A PC-based data acquisition system built at the Centre for Atmospheric Sciences, IISc, was used to acquire the data from fast response sensors. This paper reports the various components of a typical MONTBLEX tower observatory and describes the actual experiments carried out in the surface layer at four sites over the monsoon trough region as a part of the MONTBLEX programme. It also describes and discusses several checks made on randomly selected tower data sets acquired during the experiment. Checks made include visual inspection of time traces from various sensors, comparative plots of sensors measuring the same variable, wind and temperature profile plots, calculation of roughness lengths, statistical and stability parameters, diurnal variation of stability parameters, and plots of probability density and energy spectrum for the different sensors. Results from these checks are found to be very encouraging and reveal the potential for further detailed analysis to understand more about surface layer characteristics.
\end{abstract}

Keywords. Atmospheric surface layer; sensors; tower instrumentation; data quality.

\section{Introduction}

The tower platform has now been established as a standard and most convenient facility to make experiments in the surface layer, and to some extent beyond it, in the Atmospheric Boundary Layer (ABL). There are permanent tower observatories established for a continuous programme of boundary layer research, like for example the $300 \mathrm{~m}$ tower of the Boulder Atmospheric Observatory (BAO), Colorado, USA (see Kaimal and Gaynor 1983 for details) and the $200 \mathrm{~m}$ tower of KNMI, Cabauw, Netherlands (see Driedonks et al 1978 for details).

The variables of greatest interest to boundary layer meteorologists are the mean and fluctuating components of wind velocity, temperature and humidity. The stability of the layer at any time is obtained mainly using mean parameters, and the fluctuating quantities are required to describe the turbulence structure within the layer. The adequate measurement of these quantities in the surface layer makes stringent demands on the instrumentation system used to probe the layer.

Sensors for measuring the time-averaged properties of the flow should have a high degree of absolute accuracy and long-term stability. Sensors for measuring turbulent properties of the flow should have a broad frequency response to account for all the eddy scales contributing to the process. The response time for mean sensors can be as 
long as a minute but for the fluctuation sensors it should be no more than $0 \cdot 1 \mathrm{~s}$. The above requirements have been kept in mind while designing the instrumentation system for MONTBLEX.

It is a well known fact now that our understanding of the ABL has to depend in large part on observational studies. The Kansas and Minnesota experiments (see Kaimal and Wyngaard (1990) for details) are regarded as important milestones in boundary layer research. As far as tower observations in India are concerned, a beginning was made by the pioneering efforts of a group from the Indian Institute of Science (A Prabhu, R Narasimha and their co-workers), who carried out observations for the first time in India using an instrumented $10 \mathrm{~m}$ tower (Narasimha et al 1981) on the shores of the Bay of Bengal (near Balasore, Orissa) as a part of MONEX in 1979. This led to a growing interest in the understanding of $\mathrm{ABL}$ processes in the Indian monsoon region, and provided a strong base and motivation to MONTBLEX.

A careful experiment in the atmospheric boundary layer demands a variety of measurements involving various atmospheric parameters on different time scales, including in particular multi-point observations spread over the height of the $\mathrm{ABL}$ which itself varies in time and space.

Preparation and observation phases of the MONTBLEX lasted from 1987 to 1990, with a pilot experiment in 1989 and the full-scale experiment during the monsoon period in 1990. The group from the Indian Institute of Science(IISc) was responsible for installation and carrying out tower observations at three stations, viz. Kharagpur, Varanasi and Jodhpur. IIT Delhi upgraded an earlier platform to the standard $30 \mathrm{~m}$ tower for MONTBLEX and experiments during the observational phase were assisted by the IISc group. Thus there were in all four $30 \mathrm{~m}$ towers for surface layer observations. The tower sites were selected so that they covered the deep moist convective region (Kharagpur) at one end of the monsoon trough, the dry convection in the desert region (Jodhpur) at the other end, and the transition zone in-between (Varanasi, Delhi).

Conducting a field experiment in the atmosphere is itself an enormous exercise. The interpretation of the data acquired, recorded through various sensors and instrumentation, is equally important in deriving an understanding of the physics of the atmosphere. First of all, it is essential that data from the field experiments are thoroughly checked and validated before using them for detailed analysis. A section is devoted to the discussion of results obtained during such an assessment of the quality of the MONTBLEX tower data including many of the checks suggested by Kaimal (1990) for the validity of the field data on $A B L$, but we begin with the tower instrumentation-set up used in the experiment.

\section{Tower instrumentation}

The complete tower instrumentation system used for the experiment may be broadly grouped into three components, viz. the tower platform, sensors and signal conditioning units, and the data acquisition system. The block schematic of a typical tower instrumentation system is shown in figure 1.

\subsection{The tower platform}

The tower is a $30 \mathrm{~m}$ high, guyed, uniform triangular lattice structure designed to 


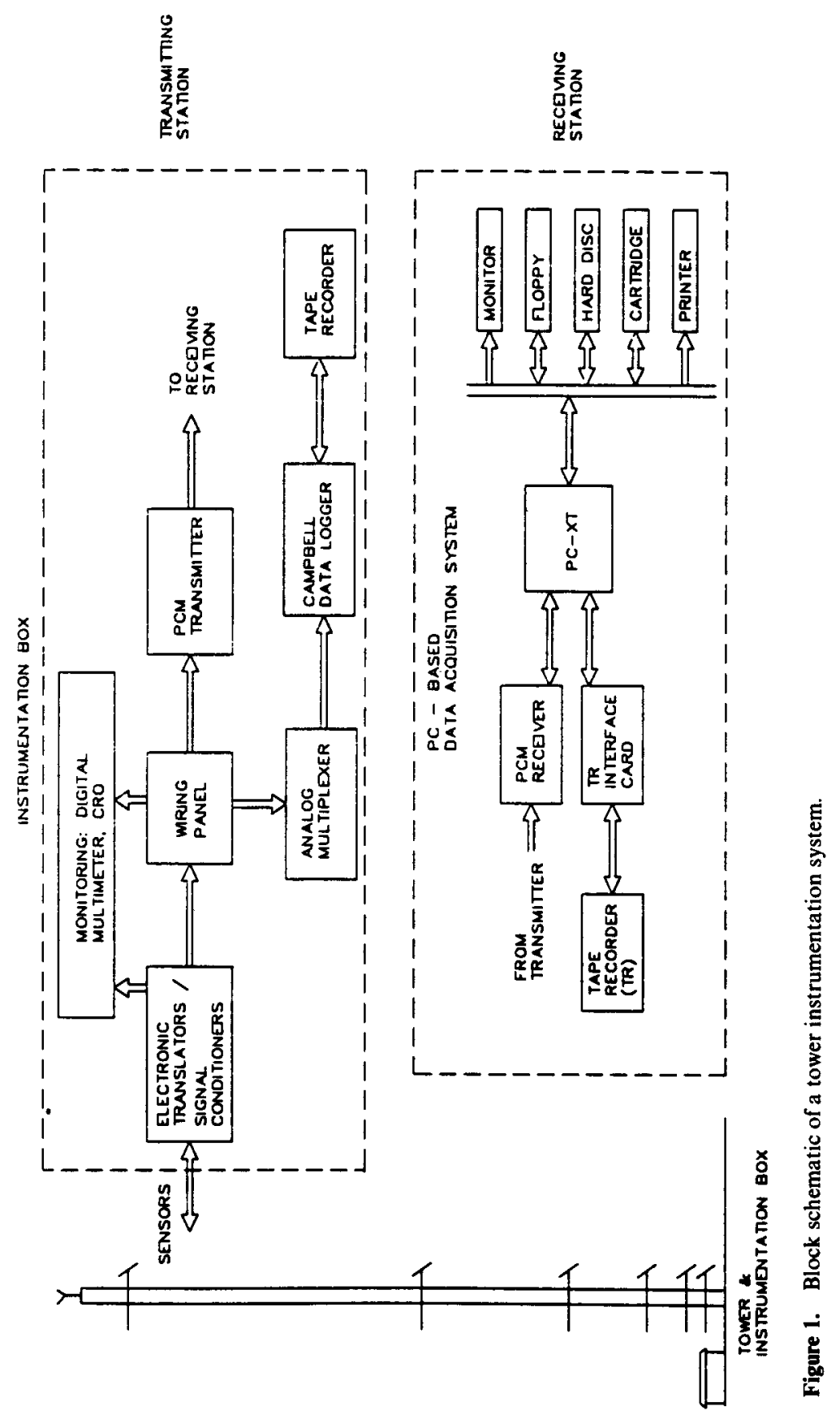


withstand a windspeed of $180 \mathrm{~km} / \mathrm{hr}$. Booms are fitted at 6 levels $(1,2,4,8,15,30 \mathrm{~m})$ with horizontal arms attached to these booms at a distance of about $1.3 \mathrm{~m}$ from the body of the tower. On these horizontal arms instrument posts are placed for mounting the sensors. Figure 2 shows a picture of an instrumented boom. The booms are designed so that they can be partially rotated about the vertical and horizontal axes to facilitate the orientation of the sensors towards the prevailing wind of the season and to ensure the horizontality of the instrument posts. This rotational facility also makes the mounting of the sensors on the instrument post easier. This is the improved version of an earlier simple boom which could be moved only in a direction perpendicular to the tower and without any rotating facility.

\subsection{Sensors and signal conditioning units}

The sensors mounted on the instrumentation posts of the booms are connected to their respective electronic translators (signal conditioning units) which are racked in a weather-proof instrumentation container at the foot of the tower. This container is placed permanently on one side of the tower opposite the mean direction of the prevailing wind of the season. The translators contain the electronics to process the signal output from each sensor and to convert it to the dynamic range of the data acquisition system. Translators also supply power to the small electronic circuit attached to the sensor, and are equipped with built-in electronics for calibration.

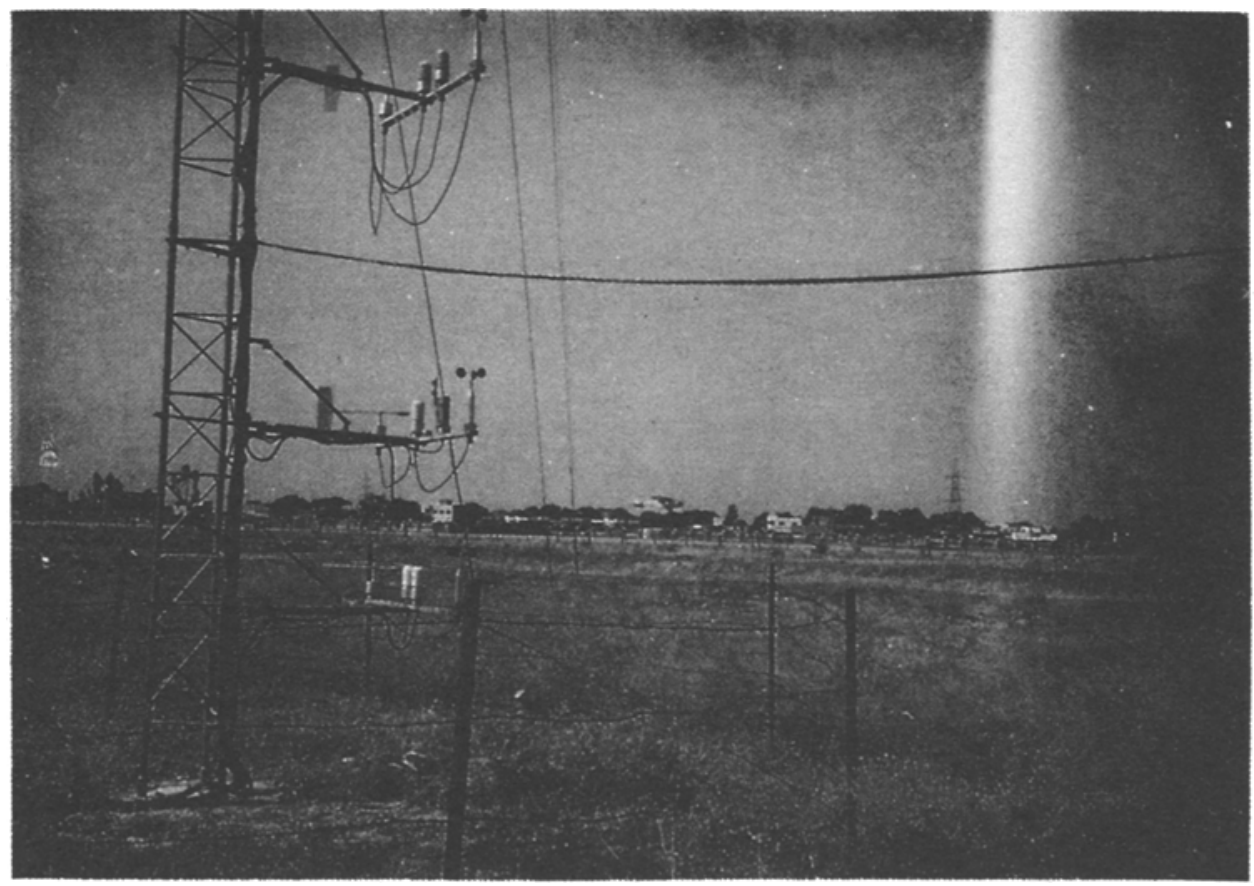

Figure 2. Picture of an instrumented boom. 
The set of sensors/instruments used and the parameters they measure are listed below.

- Cup anemometer - horizontal wind speed.

- Wind vane - wind direction.

- Gill and hotwire anemometers - three components of wind velocity.

- Sonic anemometer - three components of wind velocity and temperature.

- Platinum resistance thermometer devices (RTDs) - mean and fluctuating temperature.

- Humicaps - relative humidity.

- Lyman-alpha - absolute humidity.

- Soil temperature sensors (encapsulated platinum wire).

- Rain-gauge instrument.

- Solar radiation sensor.

Among these, the cup, Gill and hotwire anemometers, the wind vane, the platinum wire thermometers, and the relative humidity and Lyman-alpha instruments were made by Sunshine Enterprises, Bangalore. The sonic anemometers were imported from USA (made by Applied Technologies, Colorado). The rain-gauges were from Dynalab, Pune, India and the solar radiation sensors were from LI-COR Inc., USA. A brief description of each of these sensors, together with their specifications, is given in the following paragraphs.

2.2a Cup anemometer: The 3-cup anemometer works on the principle that the rotational speed of the rotor due to differential drag on the cups is directly proportional to the wind speed perpendicular to the rotor axis (i.e. horizontal wind speed). The electronic conditioning unit is designed to accommodate wind speeds in the range $0-50 \mathrm{~m} / \mathrm{s}$. The sensor has a low starting threshold of $0.5 \mathrm{~m} / \mathrm{s}$, an accuracy of $1.5-2 \%$ full scale and a distance constant of less than a metre.

$2.2 \mathrm{~b}$ Wind vane: This consists of a vane that rotates on a vertical shaft to orient itself in equilibrium to the mean direction of the wind. The variation in resistance of a $10 \mathrm{~K}$ potentiometer coupled to the shaft is converted to voltage, which is then proportional to the wind direction in the range $0-360$ degrees. This instrument has an accuracy of \pm 3 degrees, a threshold of $0.5 \mathrm{~m} / \mathrm{s}$ and a distance constant of $5 \mathrm{~m}$.

2.2c Temperature: Mean and fluctuating components of both air and soil temperature are measured using RTDs. Standard RTDs are thin platinum wires of about $12.5 \mu \mathrm{m}$ diameter and are usually encapsulated in ceramic. They have a known and constant coefficient of temperature. The change in resistance of the device with temperature is measured on a precision bridge and converted to a linearly varying dc voltage proportional to the temperature.

These RTDs have a response time of $3 \mathrm{~s}$ or better, and an accuracy of $0.2 \%$ of the full scale range of 0-50 degree centigrade. Their sensing elements (platinum wires), when used without encapsulation, measure the fluctuating component of the temperature with a response time of approximately $0.01 \mathrm{~s}$. We have used both the types to measure the mean and the fluctuating components of temperature. These sensors are mounted on the tower boom with a self-aspirated radiation shield. 
2.2d Relative humidity: Relative humidity is measured by humicap sensors made by Vaisala, Finland, with the characteristic that the capacitance of the sensor changes linearly with change in the relative humidity. The change in capacitance in turn varies the frequency of an oscillator, which is then converted to a varying voltage using a signal conditioning electronic circuit. The accuracy of the instrument is $\pm 2 \%$ in the range $10-90 \%$ relative humidity, and the response time is 10 s for $5 \%$ to $90 \%$ change in the relative humidity. The sensing element is provided with a self-aspirated radiation shield.

2.2e Gill anemometer: This is a three-component wind speed measuring instrument, but employs polystyrene foam propellers moulded in the form of true helicoids. The propeller provides one revolution for each $30 \mathrm{~cm}$ of passing wind and responds only to that component of the wind which is parallel to the axis of rotation of the propeller. The number of revolutions per second of each propeller is used to generate an analog output proportional to the magnitude of the wind component along the respective axis, the direction of rotation being used to get the direction of the wind component.

The accuracy, threshold, distance constant and range are respectively $\pm 1 \%$, nearly equal to zero, $0.6 \mathrm{~m}$ and $\pm 20 \mathrm{~m} / \mathrm{s}$.

2.2f Sonic anemometer: This is a three-axis sonic wind system from Applied Technologies, Inc., USA (model SWS-211/3KE). It uses a pair of ultrasonic transducers for each axis and operates on the principle of measuring the transit time difference between ultrasonic pulses travelling a known distance $(15 \mathrm{~cm}$ in this case) along and against the wind component parallel to the axis. From these transit times, the $u, v$ and $w$ components of the wind velocity are computed. The streamwise component of velocity can be computed as $\left(u^{2}+v^{2}\right)^{1 / 2}$. The virtual temperature of the air is also obtained from the transit times for the $w$ axis. The basic sampling frequency in the system is $100 \mathrm{~Hz}$, which is then brought down to $10 \mathrm{~Hz}$ by averaging over 10 samples. The instrument can be used as a stand-alone unit, and its serial output directly connected to any monitor screen with a serial interface. Analog signal outputs can be obtained with the help of a separate unit also supplied by the manufacturer. These can be recorded along with analog outputs from other instruments through a common data acquisition system, to be described in $\$ 2.3$. The accuracy of this instrument is $\pm 0.05 \mathrm{~m} / \mathrm{s}$ for velocity components and $\pm 1 \%$ for temperature measurements. This is designed for a range of $\pm 20 \mathrm{~m} / \mathrm{s}$ in horizontal directions $(u, v)$ and $\pm 5 \mathrm{~m} / \mathrm{s}$ in the vertical direction $(w)$. Temperature range is -20 to +50 degree $C$.

2.2g Hotwire anemometer: The hotwire anemometer used is of constant temperature type, i.e. the temperature of the wire (sensing element) is kept constant by using a servo-amplifier and an electronic feedback. The wire used is usually of platinum or tungsten with a diameter of the order of $0.5 \mu \mathrm{m}$ to $25 \mu \mathrm{m}$ and length of the order of a few millimeters. It consists of three hot wires lying on the generators of a cone, two of them to measure the horizontal velocity components and the third to resolve the vertical velocity. They are designed to measure wind components up to 10 to $15 \mathrm{~m} / \mathrm{s}$ and have a high frequency response of $10 \mathrm{kHz}$.

2.2h Rain gauge: The principle used in this instrument from Dynalab, Pune (Model RRR-100) is as follows. The rain water collected through $112.8 \mathrm{~mm}$ diameter collector 
area is converted into approximately equal-sized drops in air medium and counted electronically, sensing by means of two electrodes. The resolution is $1 / 100 \mathrm{~mm}$ of rain. The output is an analog voltage equivalent of rain rate and is refreshed at a prefixed interval of time.

2.2i Solar radiation: The sensor is a silicon photovoltaic detector supplied by LI-COR Inc., USA for measuring the incoming solar radiation. The current produced by the sensor is converted to a voltage proportional to the incident solar radiation. The sensor has a sensitivity of $0.08 \mathrm{Am}^{2} / \mathrm{kW}$ (typical), linearity of $1 \%$ up to $3 \mathrm{~kW} / \mathrm{m}^{2}$ and a response time of $10 \mu \mathrm{s}$.

\subsection{Data acquisition system}

The data acquisition system is a vital link in the tower instrumentation system. The voluminous amount of data acquired by the various sensors is made available only through this link which, apart from data logging, also provides the facility of on-line monitoring of various parameters for quick-look evaluation of the quality of the data. We used two logging systems in our experiment: a small compact data recorder placed at the tower base for recording mean data (based on Campbell's data logger), and an IBM-compatible PC-based system mainly for recording fast response sensor data using a pulse-code modulated (PCM) telemetry system. The conditioned outputs from the translators are given simultaneously (whenever required) to both the Campbell data logger and the fast data acquisition system with the help of a wiring panel. From figure 1 it may be noted that the sensors, the signal conditioners, the wiring panel, the data logger multiplexer and the cassette tape recorder form the slow data link. The fast data link departs after the wiring panel and goes through the PCM transmitter, the transmission link, the receiver card and the PC with storage devices such as hard disk and the cartridge tape recorder.

2.3a The data logger: This data logger (type $21 \mathrm{X}$ micrologger) from Campbell Scientific, Inc., USA, used to record data from all the slow response sensors, can take a maximum of 16 channels. To accommodate more channels, six of the 16 channels are multiplexed to take six additional channels each, providing in all $36+10$ channels. The data logger has its own instruction set using which it can be programmed to sample each channel at a specified interval, average the data over a specified number of sample points, convert them into engineering units using specified multiplication factors and store them on audio cassette tapes. The display on the data logger facilitates on-line monitoring of atmospheric variables being recorded.

2.3b Fast response data acquisition system: This PC-based system intended to record data from fast response sensors was fully developed at the Centre for Atmospheric Sciences, IISc. It consists of a PCM telemetry system interfaced to the PC and a userfriendly data acquisition software which runs on the computer. Both PCM telemetry system and the data acquisition software are described in detail in separate reports (Rudra Kumar et al $1990 \mathrm{a}, \mathrm{b}$ ), so they are discussed only briefly here.

The PCM telemetry system consists of a transmitter, a transmission link and a receiver. Both transmitter and receiver are designed around the Intel 8 bit microprocessor 
$8085 \mathrm{~A}$. The block schematics of the transmitter and the receiver are shown respectively in figures 3 and 4.

- Transmitter: The transmitter can be programmed through a DIP switch to take a specified number of analog channels in the range 1-64. It selects these channels one at a time using analog multiplexers (CD 4051), and encodes them in digital form using PCM with the help of an analog-to-digital converter (AD574) of 12 bit resolution. The converted digital data are then read into the microprocessor at regular intervals determined by the sampling rate, using a programmable input/output device (8155), and presented in a form acceptable to a parallel-to-serial converter (8251A) for serialisation. The serialised data are driven by a line driver (8T13) onto the transmission link. A 12-bit synchronising code is also sent in the beginning of each data set to demarcate successive data sets. The complete operation of the transmitter is governed by the software programmed into a 4 kbyte program memory (EPROM 2732A). The input parameters, namely number of channels (user selectable) and the frequency of transmission (set to $10 \mathrm{kHz}$ using another DIP switch), are read into the system using another programmable input/output device (8255A). The timer section of $8155 \mathrm{~A}$ is appropriately programmed to generate a $10 \mathrm{kHz}$ square wave. Also the memory (256 bytes) of this IC chip is used as a scratch pad for intermediate storage and stack operations.

The transmitter is usually placed inside the instrumentation box at the tower. The transmission link is a twisted pair of wires carrying the serial output from the transmitter to the receiver in a computer room usually located at a distance of 100 to

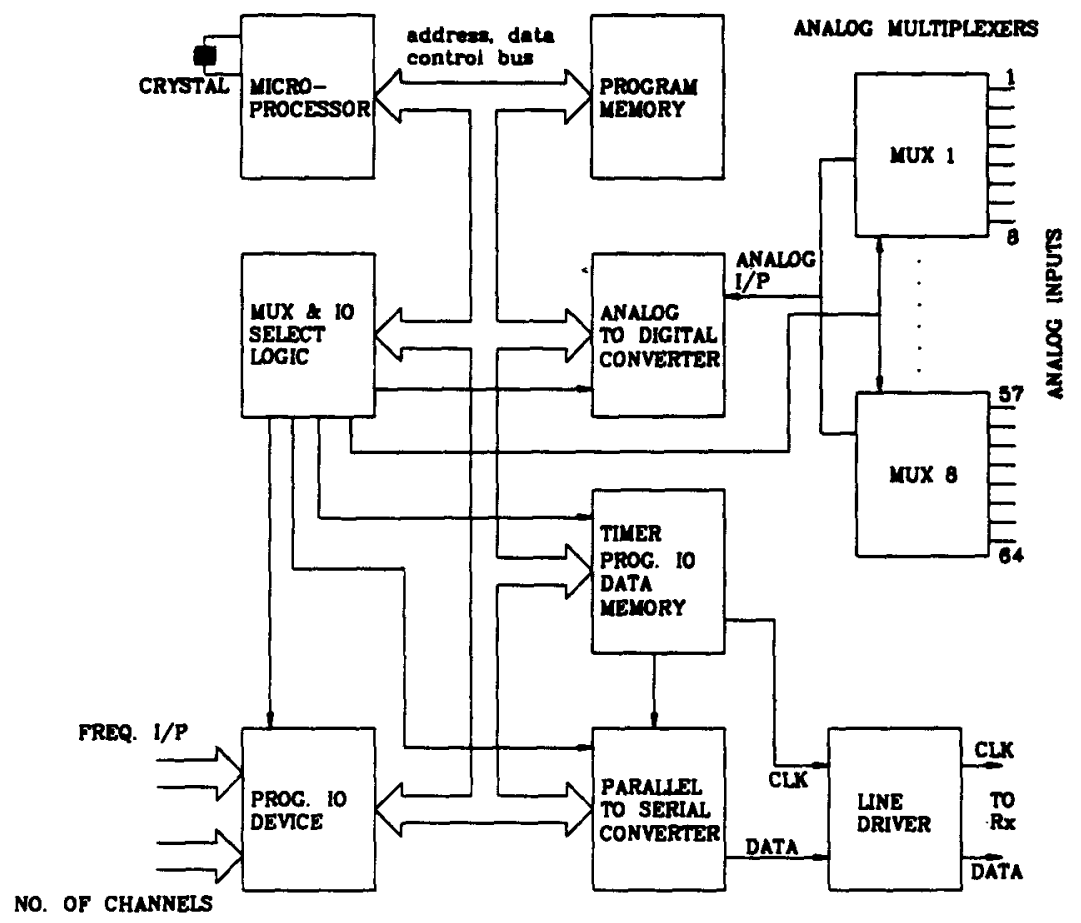

Figure 3. Block schematic of the PCM transmitter. 


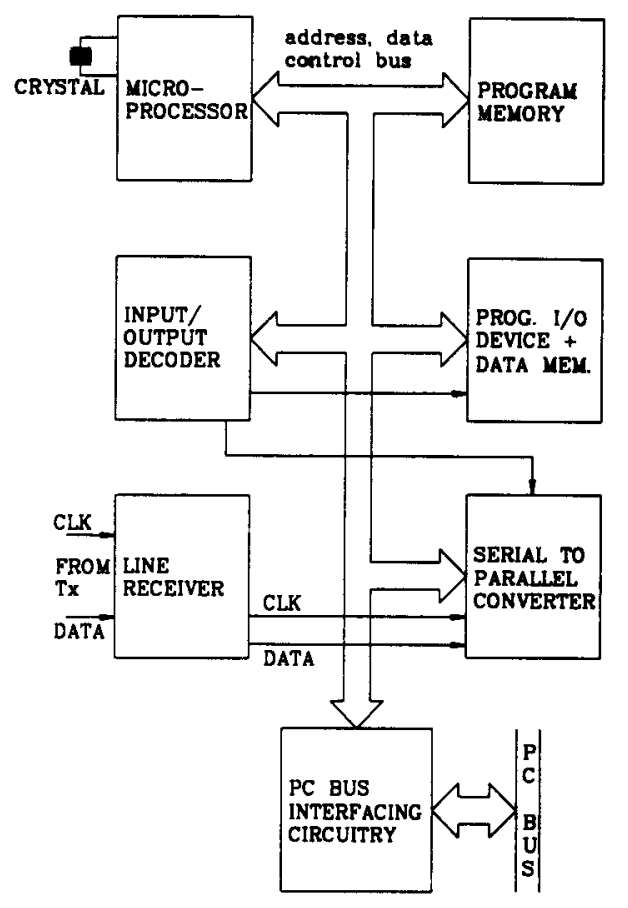

Figure 4. Block schematic of the PCM receiver.

$200 \mathrm{~m}$ from the tower. The electronics at the transmitter is designed to drive the signal to a maximum of $200 \mathrm{~m}$.

- Receiver: The receiver is designed to sit directly on the PC peripheral bus as an addon card. The first unit on this card is a line receiver (8T14) which receives the incoming serial data and presents it to the next stage of serial-to-parallel conversion. The clock used for the conversion is the same signal that is generated and used at the transmitter end, and is brought to the receiver through a line driver and a line receiver on a separate line. The on-board microprocessor $(8085 \mathrm{~A})$ with software burnt into a 4 kbytes memory (EPROM 2732A) programs appropriately the ICs $8251 \mathrm{~A}$ and $8155 \mathrm{~A}$. The $8251 \mathrm{~A}$ converts the received serial data to parallel form and presents them to the microprocessor. The processor first detects the sychronising code and then onwards, interrupts the PC after every serial to parallel conversion of 12 bits, which is the resolution of the analog-to-digital converter used in the transmitter and corresponds to the output of one sensor. The PC, in its interrupt service routine, reads the data available at the output port of the $8155 \mathrm{~A}$ and stores is for further processing. Here also, the memory available in the $8155 \mathrm{~A}$ chip is used for intermediate storage and stack operations.

2.3c Data acquisition software: The data acquisition software which runs on the computer is user-friendly, menu-driven and flexible, and provides various convenient features. Variables like the number of channels, number of data samples to be averaged on each channel before storing, time interval to display on the screen (on-line) the mean values of a set of sensor outputs and the duration of the data acquisition can all be 
programmed prior to the beginning of the acquisition experiment. The channel table, which gives details such as channel number, the sensor connected, units of measurement and multiplication factor, can be viewed and if necessary appropriately modified according to the actual physical connections of sensors on the tower. Date, start time and end time of acquisition are automatically stored using the real time clock facility of the PC. Any additional signatures like the experiment number and the synoptic conditions (which are useful during post-processing) around the tower may also be entered using the appropriate options of this menu-driven data acquisition software.

The option of automatic recording (unattended data acquisition) is also provided, using which the data can be recorded in the absence of the experimentalist. This option is particularly useful to record data during night. When this is exercised the additional input of duration between successive experiments is to be entered. The data acquisition software finally stores the data on the PC hard disc in binary form; this is necessary because the higher sampling rate needs large memory, and binary data converted to engineering units requires larger area for storage. However the facility of on-line monitoring of a set of variables ( 6 channels at a time) in engineering units on the screen of the computer provides the check that is necessary in this kind of experiment. The data stored on the hard disc can be transferred regularly to cartridge tapes through the cartridge tape drive (TVSE make TD 1060i) connected to the PC.

\section{Sites}

Before going into the details of the observations made at all the four tower stations, a brief look around the tower platforms is given below.

The towers in Kharagpur, Varanasi and Jodhpur are located in farm fields. From the point of view of a clean fetch Kharagpur is perhaps the best site among all, as it has a long stretch of open and flat surface towards the south (nearly $1 \mathrm{~km}$ ), which is the mean direction of prevailing wind during the season. Figure 5 shows a picture of terrain and fetch at this site. The data acquisition computer is placed in a small room of about $3 \mathrm{~m}$ height situated at a distance of about $150 \mathrm{~m}$ north-east from the tower.

The Varanasi tower also has an open field towards the south and a small building of $3 \mathrm{~m}$ height, situated at a distance of about $15 \mathrm{~m}$ towards the west of the tower, which houses the data acquisition computer. There is a wind mill $(8 \mathrm{~m}$ high) towards the south-west at a distance of about $25 \mathrm{~m}$. Figure 6 shows a picture of this site.

At the Jodhpur tower (figure 7) we see fairly good open space around the tower with a few small plants of less than $0.5 \mathrm{~m}$ height grown for research purposes towards the west and north-west. A few, small bush trees of 1 to $2 \mathrm{~m}$ height, present closer to the tower during the installation (seen in the picture), were cut before the experiment started. A $6 \mathrm{~m}$-high building is located at about $100 \mathrm{~m}$ from the tower towards the west and the data acquisition computer is placed inside this building.

At the Delhi tower, the nearest structure, located towards the east at a distance of about $15 \mathrm{~m}$, is a small room of $3 \mathrm{~m}$ height, in which the computer and the data logger are placed. Raman et al (1990) have described this site with a picture of the tower (when it was $20 \mathrm{~m}$ high).

The pictures presented in this section are taken from the album of pictures photographed during the installation of tower platforms by the IISc group at Kharagpur (1988), Varanasi and Jodhpur (1989-90). 


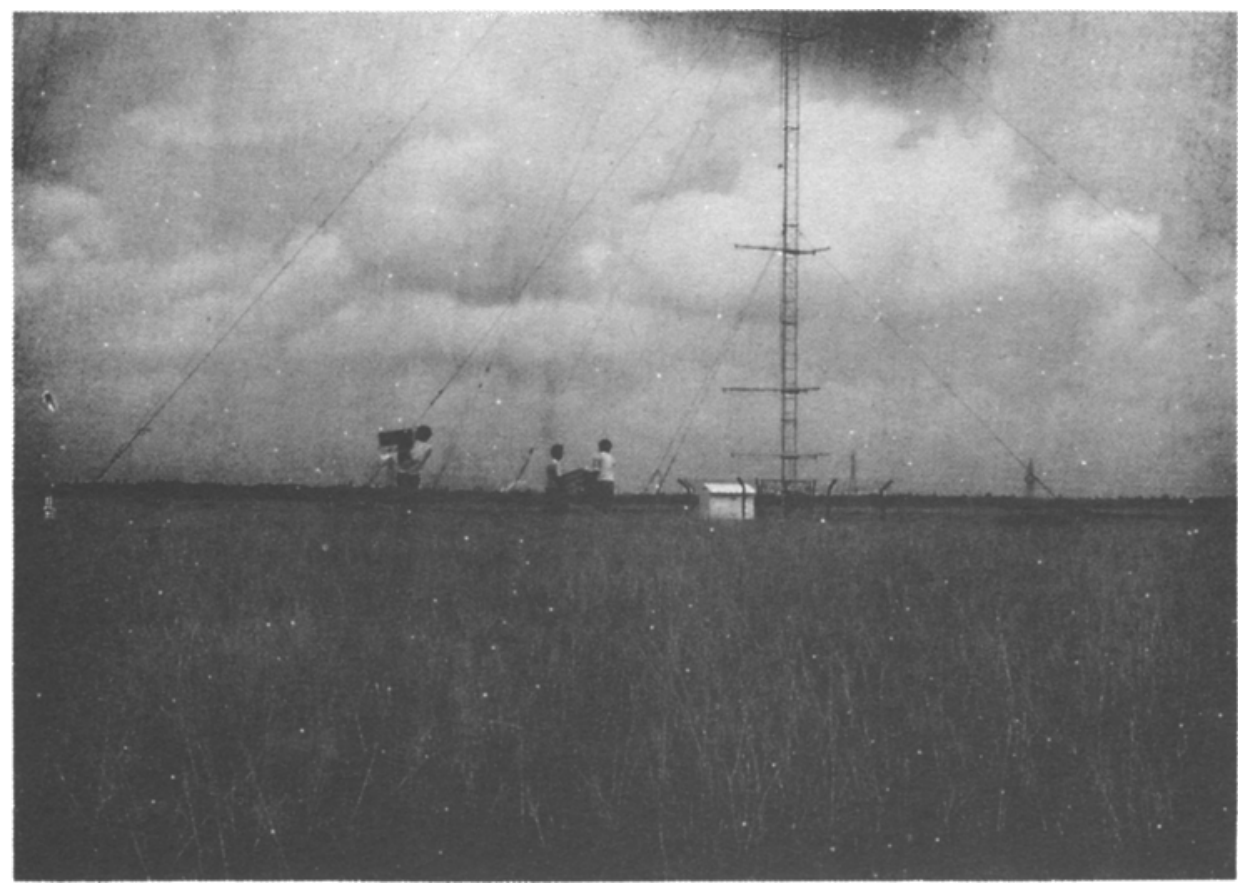

Figure 5. A picture of the Kharagpur site showing fetch and terrain.

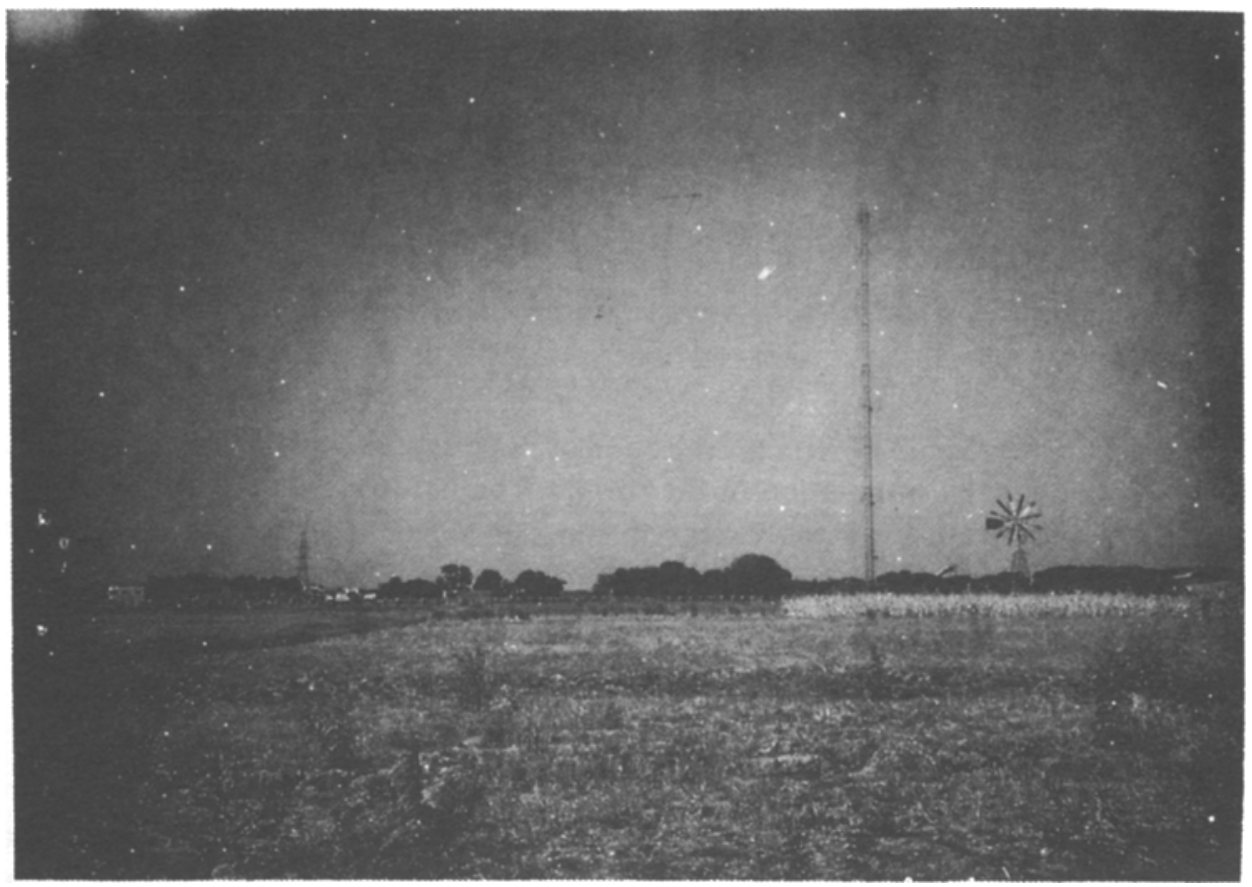

Figure 6. Terrain and fetch at the Varanasi tower. 


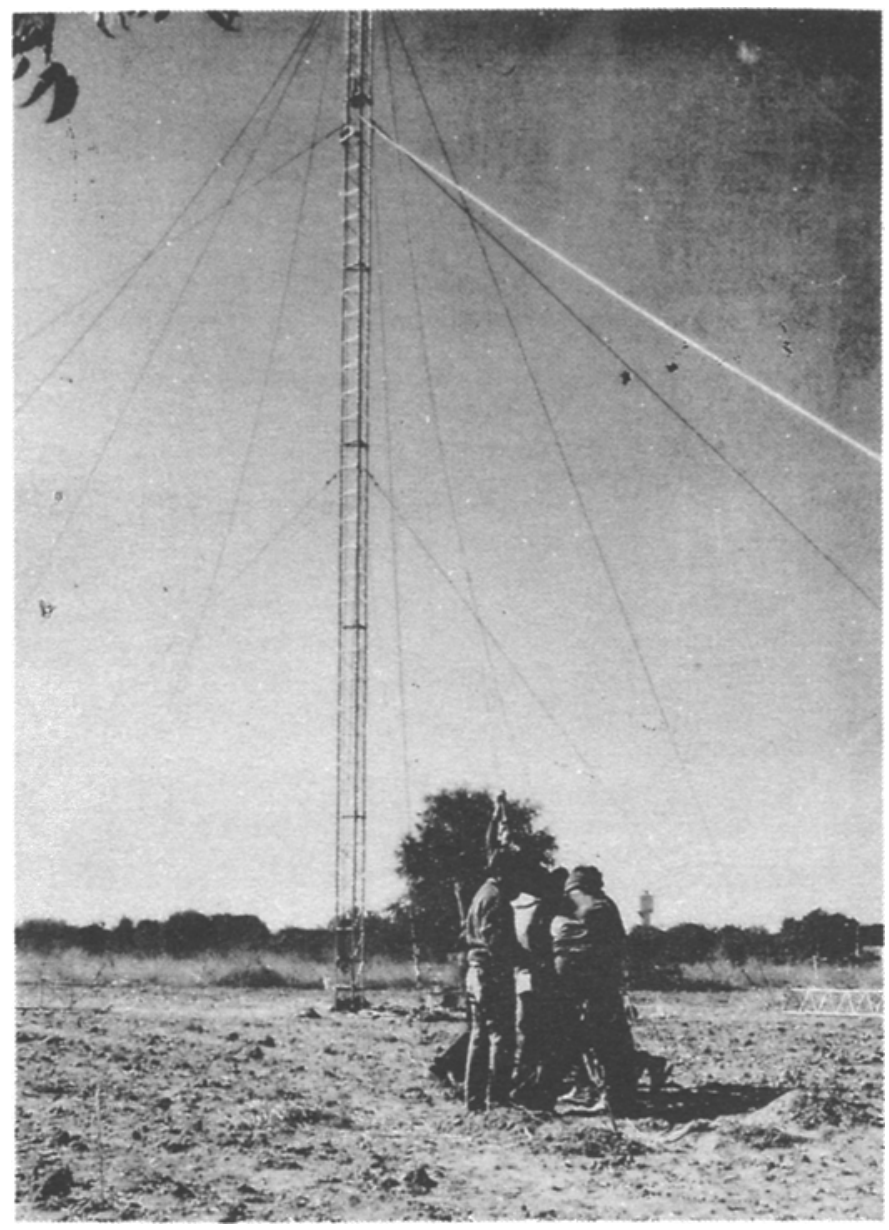

Figure 7. A picture of the Jodhpur site during tower erection.

\section{The experiment}

Preparations began in 1987 with the selection of suitable sites at Kharagpur, Varanasi and Jodhpur for the installation of the towers. The hardware and software for the PC-based data acquisition was designed and developed at the CAS, IISc. In the summer of 1988 a $30 \mathrm{~m}$ tower was installed in the air field at IISc and a preliminary exercise was carried out. The tower was later transported to Kharagpur.

\subsection{Pilot experiment at Kharagpur}

The Kharagpur tower was installed in the agricultural research field on the IIT Kharagpur campus in the last week of July 1988. The pilot experiment was carried out in 1989 for a week (1st to 7 th July) mainly to test all the instruments and the data acquisition system. The observations made during this experiment have been reported 
by Prabhu et al (1990). This experiment was carried out amidst severe thunderstorm activity. There were a few break-downs of the data acquisition system due to some electronic component failures, suspected to have been caused by induced electromagnetic fields during lightning. Also, there was a frequent problem in the synchronising logic of the receiver, which forced a redesign of the PCM telemetry system (Rudra Kumar et al 1990b). The pilot experiment proved to be a very useful exercise as invaluable operational experience was gained during highly-disturbed meteorological conditions and enabled the Instrumentation Group at CAS, IISc to incorporate necessary protection against the lightning hazard in the instrumentation system.

\subsection{Main phase observations}

Installation of tower platforms at Varanasi and Jodhpur was completed by the end of January 1990. The full scale surface layer observations for MONTBLEX were conducted at all four places from the last week of May 1990 to the middle of September 1990. This duration (approximately three and a half months) was chosen to include premonsoon, as well as active and break periods.

4.2a Sensor configuration on the tower: Figure 8 shows the tower-sensor configuration at all four sites. It is seen that in general there are 6 levels of cup anemometers and wind vanes, 4 levels of slow response temperature sensors, 3 or 4 levels of relative humidity sensors, 2 levels of fast response temperature sensors, one level of sonic, Gill and hotwire anemometers, one level of Lyman-alpha instrument, 3 levels of soil temperature sensors

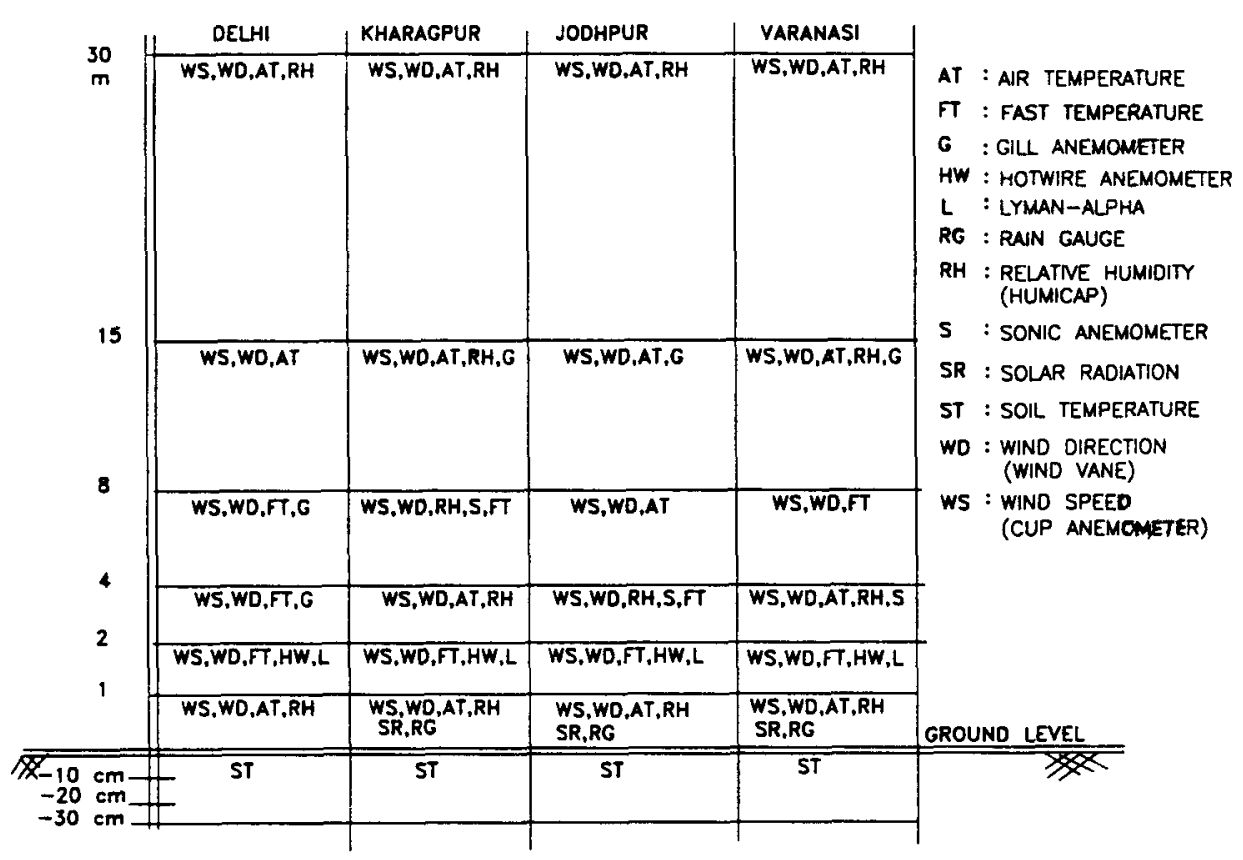

Figure 8. Tower-sensor configuration at the four field stations. 
and one each of a rain gauge and solar radiation measuring instrument. At the Delhi tower there is no sonic anemometer, rain gauge or solar radiation instrument. Also it may be seen that there is a small variation in the height at which the different sensors are on the tower among the four stations.

4.2b Data acquisition: The slow response sensors connected to the Campbell data logger were sampled at a frequency of $1 \mathrm{~Hz}$ and averaged for 3 minutes before being finally stored on audio cassette tapes. Occasionally 1 minute averaging has also been selected by the local data acquisition personnel. Data have been acquired round the clock on this data logger. Both slow and fast sensors were connected to the PCM telemetry system. Only 32 channels were used on the PCM transmitter with a known (constant) value of DC voltage connected to channel 1 as a quantitative check on the incoming data through the complete link of the PC based PCM telemetry system. Data have been recorded on this logging system in stretches usually of 15 minutes (sometimes 10 minutes when the back-up facility was not available) every hour during Intensive Observational Periods (IOPs), and every three hours at other times. The acquisition sampling rate was $8.41 \mathrm{~Hz}$. This number arises from the following parameters: transmission clock rate of $10 \mathrm{kHz}, 33$ channels (including one channel for the sync. word) of 12 bit resolution, and averaging done over 3 data samples on each channel. At the Delhi tower there was no PCM telemetry system; instead, there was a 16 channel acquisition card (from Keonics Ltd., Bangalore) on the PC, to which all the fast response and a few slow response sensor outputs were connected.

The IOPs were declared from time to time, depending on the importance of special events during the monsoon, by the MONTBLEX operation control centre (MOCC) who were closely watching the movements of the monsoon. The personnel engaged in the acquisition were advised to enter the synoptic conditions around the tower with the option provided in the menu-driven data acquisition software before acquisition of each data set. The total data files recorded on the fast response data acquisition system with the synoptic and other details have been compiled in a report by Rudra Kumar et al (1991a).

4.2c A glimpse of field experience: Simultaneous observations at different places for a duration of three and a half months was quite a challenging task. All the earlier exercises including the pilot experiment were of much shorter duration and confined to one station. Some of the difficulties which were actually faced by the observational team were not anticipated before the experiment. At each of the tower stations a group of trained personnel was enagaged in acquiring the data according to the instructions from the core team. There was one expert team of instrumentation engineers (SRK and SA were among them) travelling to and fro from east (Kharagpur) to north-west (Jodhpur) and attending to faulty instruments and break-downs (if any) in the data acquisition system. There were a few break-downs in the data acquisition system at Kharagpur and Varanasi mainly due to the failure of the PCs at these places. The only break-down at Jodhpur was due to an unusual spell of rain in the first week of July when the tower and the instrument box were in water $(\max$ of about $10 \mathrm{~cm})$ for 2 to 3 days. Even at Varanasi, the instrument box had to be lifted up due to water at the site. The time required to set right break-downs at any place depended chiefly on the current location of the expert team along the network of the tower stations! The gaps in both the fast and slow data were mainly due to the delay in the expert team reaching the 
required field station. Nevertheless, the data acquired at each of the tower stations covers varied stability conditions and all special events of the monsoon.

4.2d Calibration at site: Mean temperature and relative humidity at all levels were frequently checked against psychrometer readings and the difference was recorded in the $\log$ book. Also wind vanes were aligned to the true North once in fifteen days. The sonic anemometer was calibrated as instructed by the manufacturer (using zero-wind tubes) whenever there was a change in the transducers. Hot wire probes were calibrated at the tower using portable wind tunnels.

\section{Post-processing and final format of the data}

The data files from all the tower stations were brought to Bangalore for editing and post-processing. The fast data recorded on the PCM telemetry system (referred to as the fast data files), which were in binary form after acquisition on site, were converted to the respective engineering units and stored in ASCII format. Each fast data file was then transferred to a separate directory in which all the variables are stored as separate files. The name of the directory contains codes for the field station, month, date and time of the day as given below.

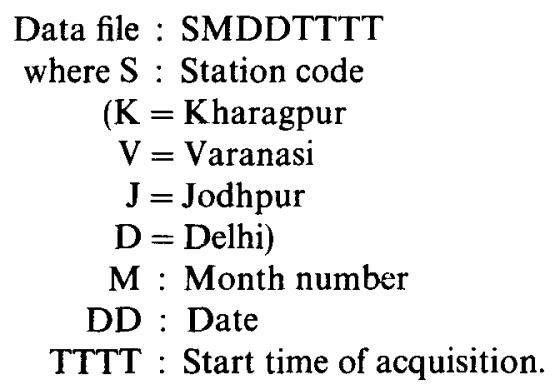

For example, the J6150900 directory (or the binary file) represents the data recorded on June 15th at Jodhpur, with the acquisition started at $0900 \mathrm{hrs}$. The names of the files stored under each of these directories give the variables with a level code attached to them $(1,2,3$, etc.), indicating the level at which the corresponding sensor was mounted on the tower. There are about 900 fast data files available for Jodhpur, 450 for Delhi, 350 for Varanasi and 300 for Kharagpur stored in about 65 cartridge tapes of 40 Mbytes capacity.

During the process of conversion of fast data files from binary form to the respective engineering units, the time trace of all the variables and the comparative plots of outputs from different sensors measuring the same variable have been visually inspected. Any discrepancies like presence of spikes, signal drop-outs and offset errors, or any other unusual behaviour seen in any variable have been separately reported (Rudra Kumar et al 1991b). Various quality checks have been made on randomly picked data sets to validate the data, and are reported in detail in a separate report (Rudra Kumar and Prabhu 1991).

For the mean variables recorded on the Campbell data logger (referred to as slow data), all the valid data corresponding to a channel, on all available days and times (for 
the whole experiment), are concatenated and stored in a separate file. The name of the file contains the station information, the variable and the level at which the sensor is mounted. For sample, Temp 1. kgp represents temperature data at level 1 from Kharagpur (.bhu, .del and .jdp have been used respectively for Varanasi, Delhi and Jodhpur). The mean variables are stored in 4 cartridge tapes of 40 Mbytes capacity.

\section{Quality analysis}

Here, we present the important results from the quality assessment exercise using various checks. A detailed technical report has been made on the assessment of quality of tower data from MONTBLEX-90 (Rudra Kumar and Prabhu 1991). The data have been selected randomly and the details such as file names and variables are printed on the figures themselves.

The first obvious check is to visually see the time series plot of the data to find out if there are any spikes or signal drop-outs. When there is more than one sensor measuring the same variable it is a good check to plot them to the same scale and check how they compare. Profile plots for mean quantities are best to see if there are any kinks indicating faulty or offset drifted sensors. Then from computed values like roughness height from the windspeed profile, stability parameters and their diurnal variation etc., the data quality may be ascertained. This distribution of data (especially the turbulence quantities) over their mean gives another check of the quality. The energy spectrum of the turbulence quantities may be seen to look for the slope of the energy decay in the inertial sub-range.

\subsection{Visual inspection of the time series data}

Time traces from various sensors are plotted to look for spikes and signal drop-outs. While plotting data recorded in the fast data files an averaging time of $1 \mathrm{~s}$ is used; i.e. each point on the plot is an average over one second.

Examples:

- Figure 9 shows time traces of cup anemometer data at all 6. levels plotted simultaneously with the origin of the successive levels shifted on the $y$-axis by a fixed value to look at any coherent structures that might be present over the height of the tower.

- Figures 10 and 11 show examples of traces of all three wind velocity components from sonic and Gill anemometers respectively.

- Figures $12 \mathrm{a}$ and $12 \mathrm{~b}$ show time series plots of mean values of temperature and relative humidity (averaged for 3 minutes) at $30 \mathrm{~m}$ (level 6) for one complete day at Kharagpur.

As illustrated by figure 9 , cup data are spike-free. Incidentally we clearly discern a coherent structure over the height of the tower. The wind components from sonic and Gill anemometers (figures 10,11) are also seen to be spike-free, but the Gill $w$ component (at all stations) is often found to have one or two spikes in 10/15 minutes stretch of data (Rudra Kumar and Prabhu 1991). The $w$ component is much smaller than the $u$ and $v$ components, and has a mean close to zero. The strong correlation between temperature and relative humidity variations seen in figure 12 suggests that the 


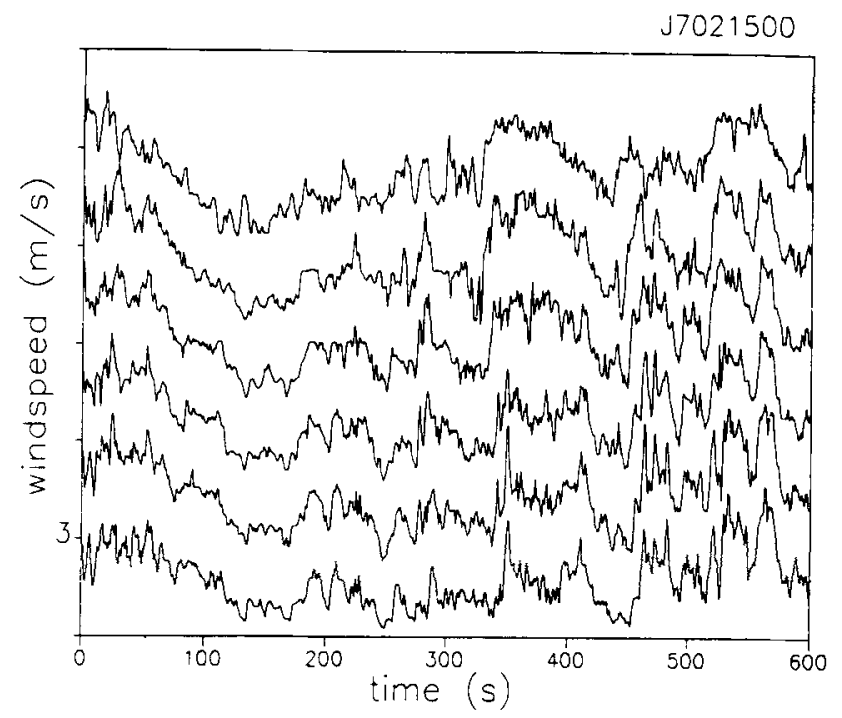

Figure 9. Time trace of cup anemometer data at all 6 levels.

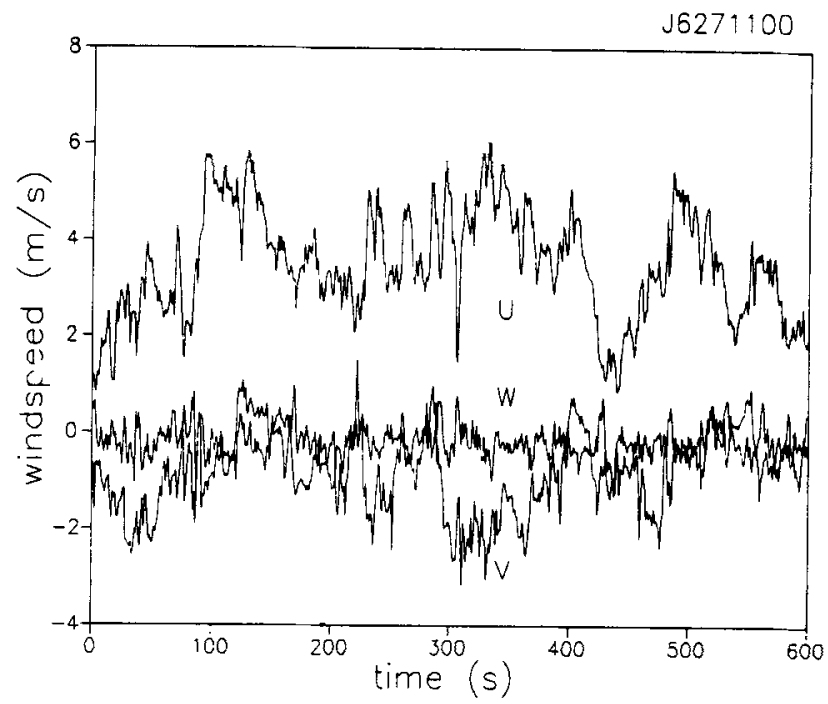

Figure 10. Time series plot of velocity components from a sonic anemometer.

different sensors and the instrumentation system are effectively recording true physical processes in the atmosphere.

\subsection{Comparison of data from different sensors measuring the same physical variable}

Figures 13 and 14 show time traces of the horizontal velocity $\sqrt{ }\left(u^{2}+v^{2}\right)$ computed 


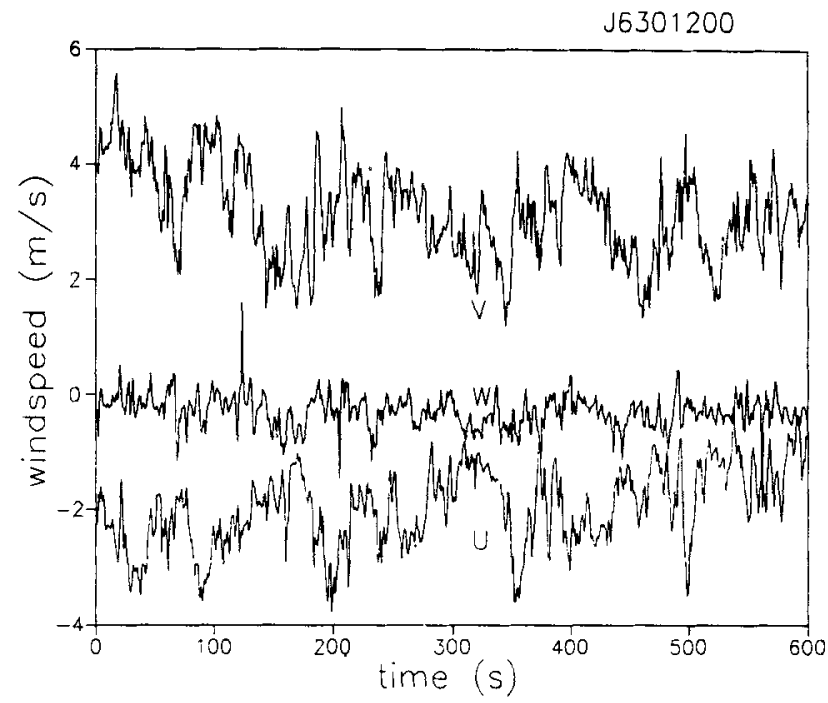

Figure 11. Time series plot of velocity components from a Gill anemometer.
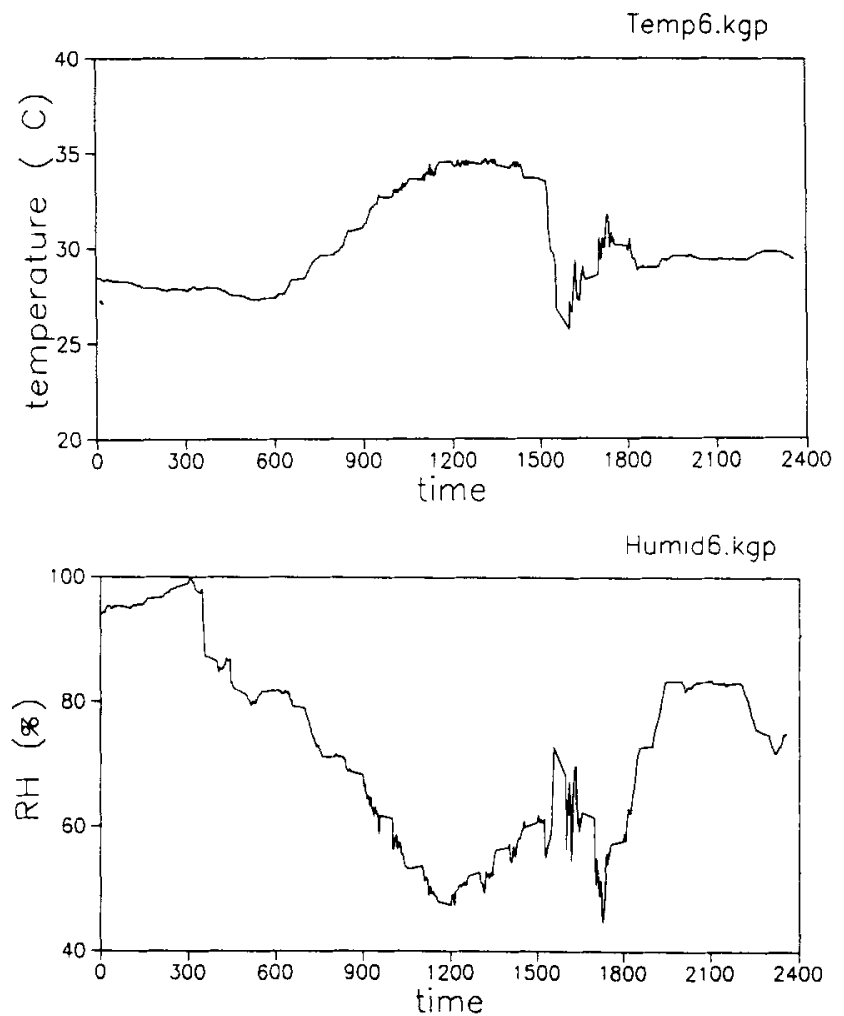

Figure 12. Three-minute averaged temperature and relative humidity data plot for one full day. 


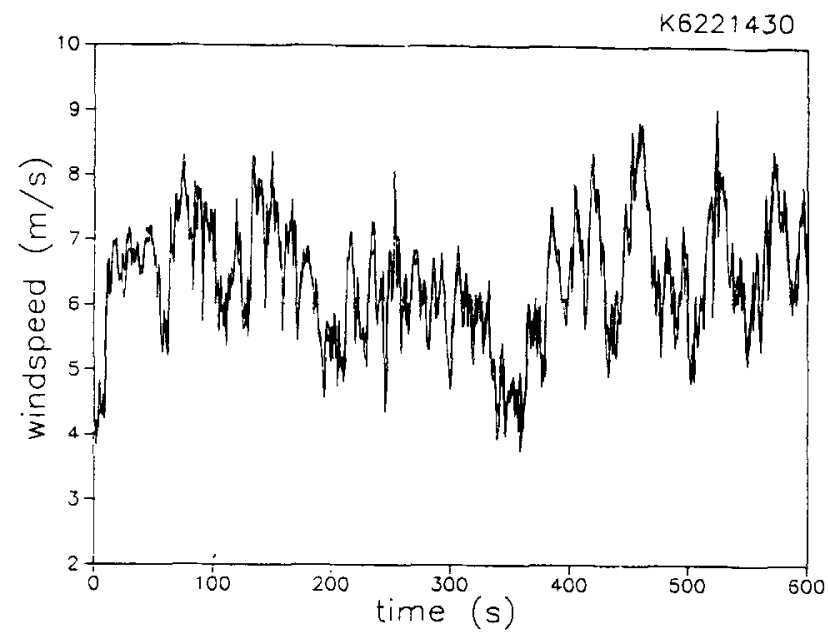

Figure 13. Simultaneous plot of horizontal windspeed from cup and sonic anemometers mounted at the same level on the tower.

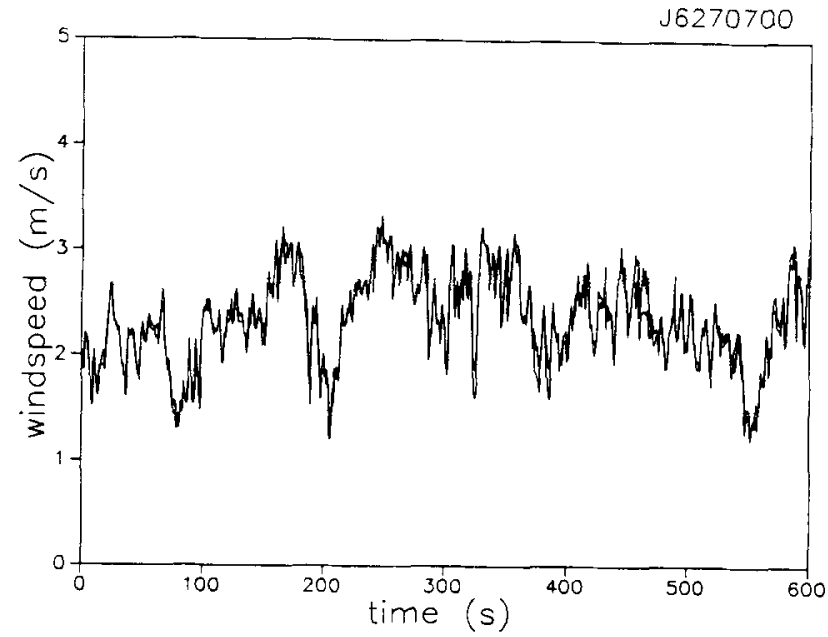

Figure 14. Simultaneous plot of horizontal windspeed from cup and Gill anemometers mounted at the same level on the tower.

from the $u$ and $v$ components recorded by the sonic and Gill anemometers, plotted over the wind speed from the cup anemometers at the respective levels on the tower.

Considering the different designs, response times and calibration procedures underlying the different sensors, the comparison made above between the sonic and Gill anemometer data with that of the cup anemometer must be considered very good. Such agreement between different sensors measuring the same physical variable (wind in the above case) proves quantitatively that these instruments are quite accurate and that the data recorded represent closely the true value of the wind in the atmosphere. 


\section{$6.310 / 15$ minute averages of time series data}

From the fast data files, the data are averaged over the complete duration (10 or 15 minutes) and plotted against the height to see if there are any kinks in the vertical profile. By this method we can obtain indications of a faulty sensor or drift in calibration at one or more levels. Here, the data from the cup anemometer and the temperature sensors (which are available at all the levels and stored in the fast data file) have been considered.

Figure 15 shows a temperature profile (solid line) without the data from the levels where fast temperature sensors are mounted $(2 \mathrm{~m}$ and $4 \mathrm{~m}$ in this case of Jodhpur). These points are also indicated in the figure and the discrepancy is reported as due to an offset error in the mean value of the fast temperature sensor (Rudra Kumar and Prabhu 1991). Figure 16 shows two wind profiles using the cup anemometer data.

From the above profile plots it is seen that care should be taken in obtaining temperature profiles. Fast temperature sensors may have an offset error in their mean level and therefore should be used with caution; they may however be used with confidence to get fluctuations. Cup data again show good reliability by the smooth structure exhibited in the vertical profile.

\subsection{Mean wind profiles and calculation of $z_{0}$}

Mean wind profiles when the stability conditions are neutral or near-neutral are plotted against height on log-linear scales and a least-squares straight line is fitted. The value of $z_{0}$ (roughness height) is obtained by extrapolating the profile linearly to zero wind and should typically be a few centimeters in open areas.

Figure 17 shows two cases (near-neutral), one each from Kharagpur and Jodhpur respectively. The value of $z_{0}(2.5 \mathrm{~cm}$, in both cases $)$ is of the same order as widely quoted

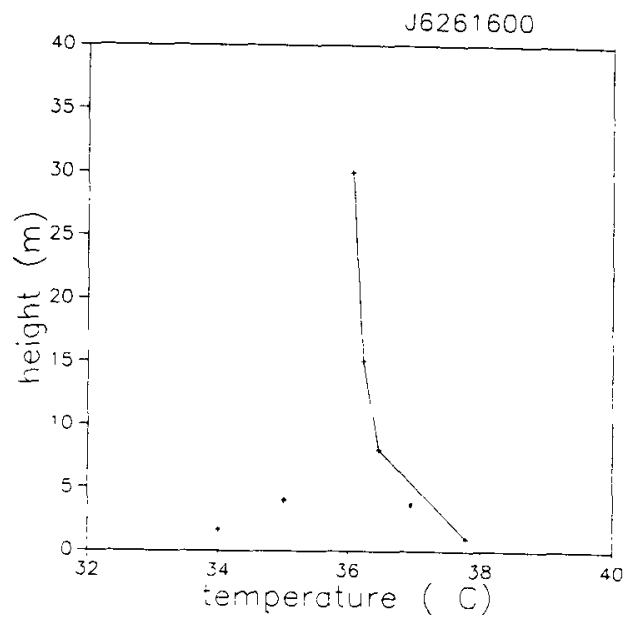

Figure 15. A temperature profile using 10-minute averaged data from slow response sensors. Points not connected at $2 \mathrm{~m}$ and $4 \mathrm{~m}$ correspond to fast response sensors. 

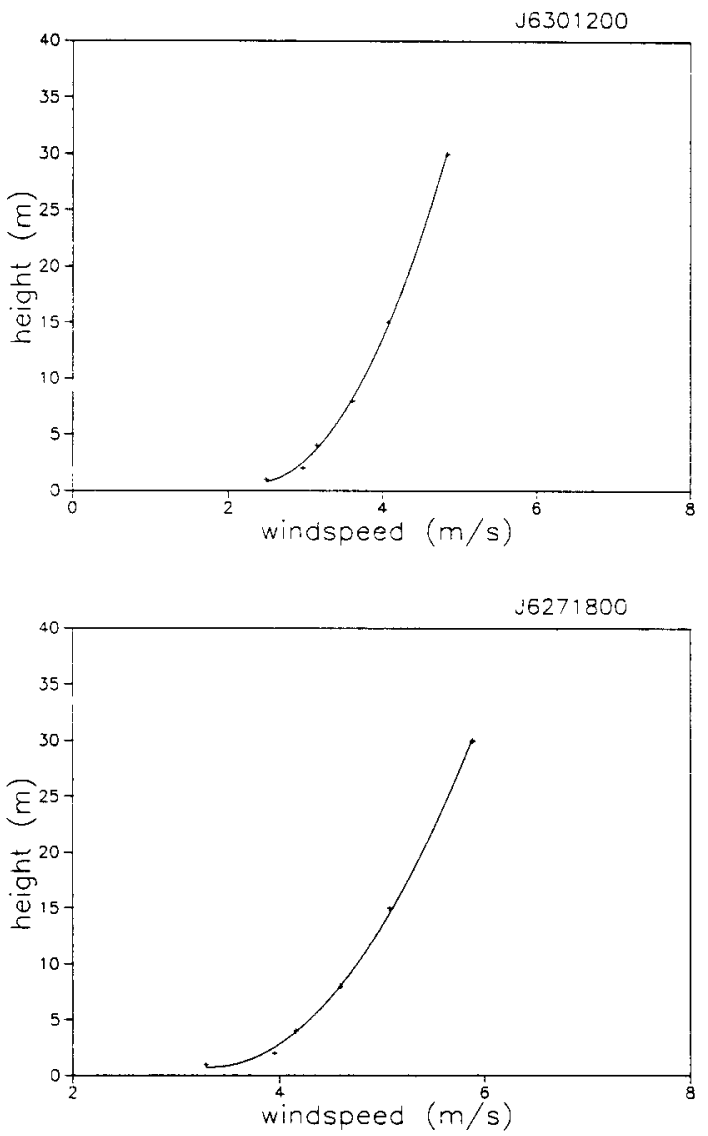

Figure 16. Typical wind profiles constructed from 10-minute averaged cup anemometer data.

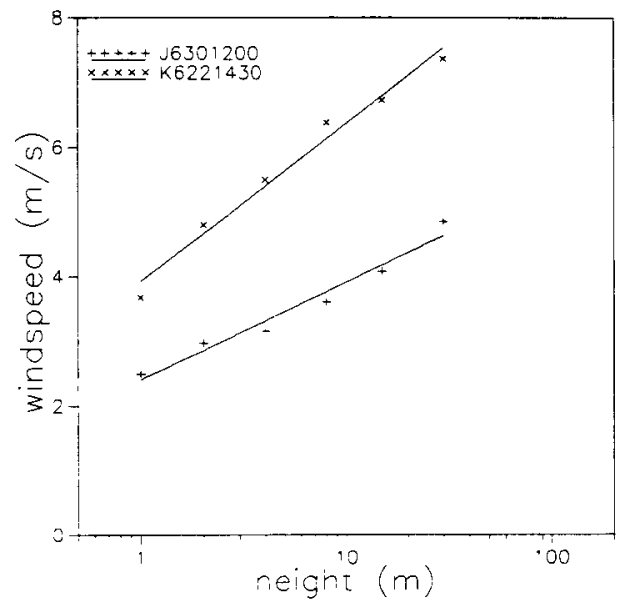

Figure 17. Log-linear plot of wind profile data (two near-neutral cases). 
for open areas (Panofsky and Dutton 1984). Both Jodhpur and Kharagpur have fairly good open space around the observational platform.

\subsection{Diurnal variation of various parameters}

We show here data from Jodhpur for one full day during an IOP (observation every hour), to examine the diurnal variation of various stability and statistical parameters. The data cover the time period from 0600 hours on 26 June to 0600 hours on 27 June 1990 without two data sets $(1300 \mathrm{hrs}$ data on 26 th has not been recorded possibly due to power failure and $0400 \mathrm{hrs}$ data on $27 \mathrm{th}$ is not considered as it was found unreliable). The following parameters are determined and plotted in figures 18 to 20 :

- Gradient Richardson number - Ri (1-15 m).

- Gradient Richardson number - Ri $(1-30 \mathrm{~m})$.

- Flux Richardson number - Rf (at $4 \mathrm{~m}$ ).

- Ratio of height to Monin-Obukhov length $-z / L$.

- Ratio of std. dev. of vertical velocity $(w)$ to friction velocity $-\sigma_{w} / u_{*}$.

- Correlation coefficient $-\mathbf{R}_{u w}$.

- Correlation coefficient $-\mathbf{R}_{w T}$.

A clear diurnal variation can be seen in various stability parameters like $\mathrm{Ri}, \mathrm{Rf}$ and $z / L$. As reported from earlier investigations using data from the Kansas experiment (Haugen et al 1971), here also we notice that $\sigma_{w} / u_{*}$ stays around 1.3 for near neutral conditions and increases for strong unstable conditions. $R_{u w}$ from the expected value of around $-0 \cdot 3$ for near neutral conditions drops to lower values during strong unstable conditions and $\mathbf{R}_{w T}$ varies from -0.4 for stable conditions to 0.7 for unstable conditions, roughly the same range as reported by Haugen et al (1971).

\subsection{Probability density of data from various sensors}

The probability density of some of the variables was also examined to check the distribution pattern. Figure 21 shows the distribution of $u$ and $w$ components from a sonic anemometer.

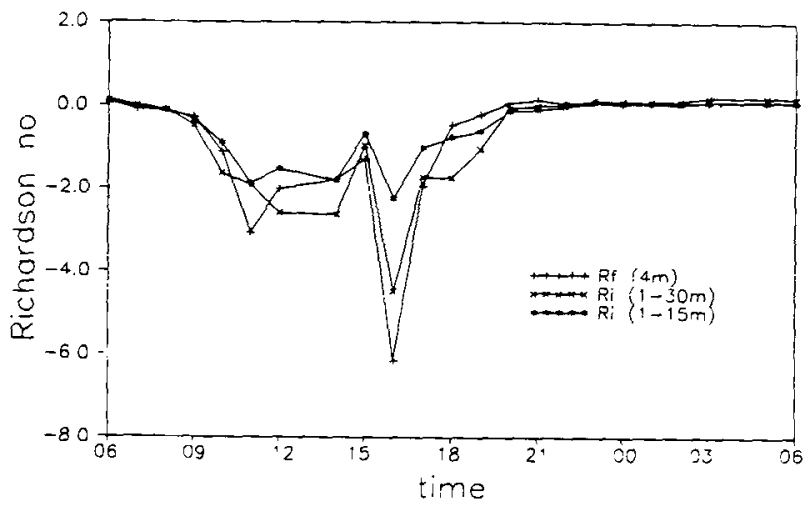

Figure 18. Diurnal variation of $\operatorname{Ri}(1-15 \mathrm{~m}), \operatorname{Ri}(1-30 \mathrm{~m})$ and $\mathrm{Rf}$ computed at $4 \mathrm{~m}$. 

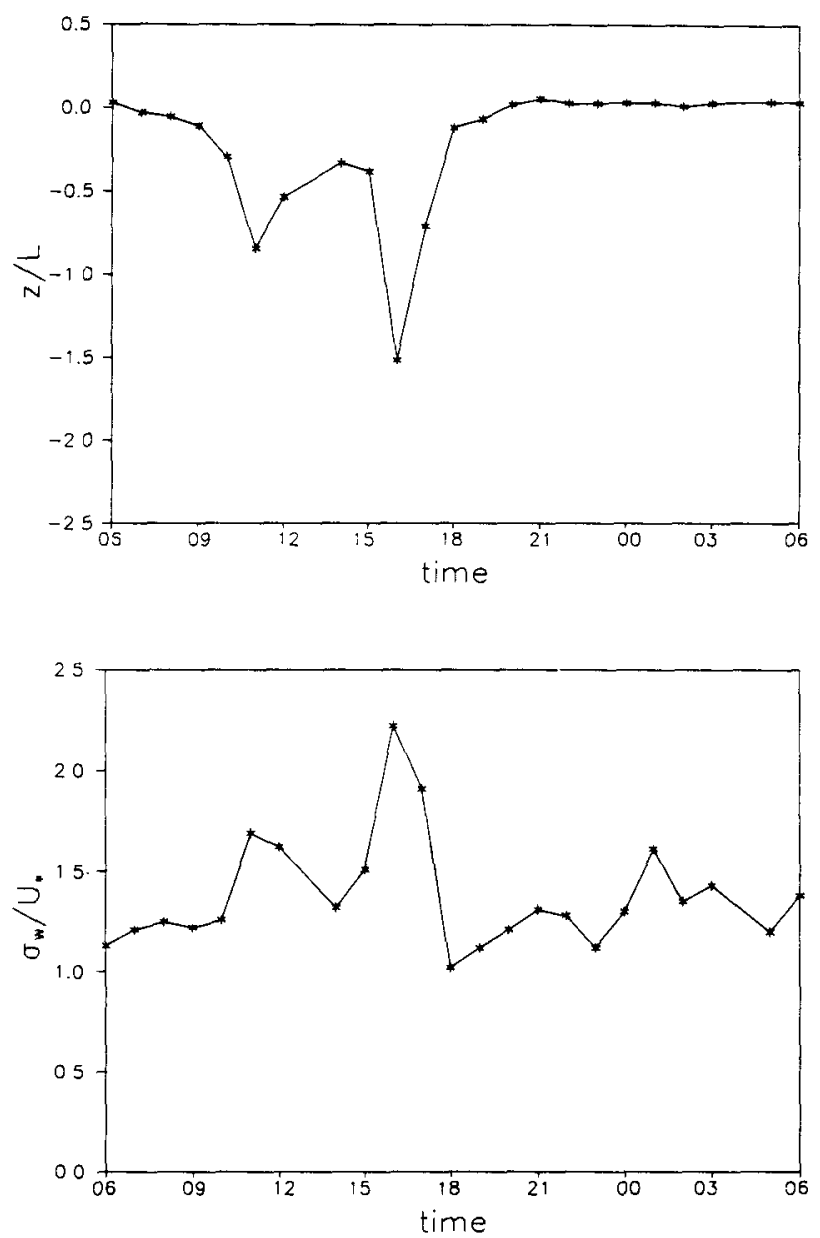

Figure 19. Diurnal variation of $z / L$ and $\sigma_{w} / u_{*}$

It is seen that the data points lie mostly within $a \pm 3 \sigma$ band around the mean (central line). Along with the distribution of the actual data (shown by symbols), the Gaussian function with the same standard deviation (shown by the full curve) is also plotted in each of the figures. It is seen that the distribution of the data closely follows the standard Gaussian over the range of observed values.

\subsection{Power spectral density}

It is well known that the spectrum of velocity, temperature and humidity fluctuations in the atmosphere decay with respect to the frequency with the Kolmogorov slope of $-5 / 3$ in the inertial sub-range. To check this we have looked at $u$ and $T$ components from the fast response sonic anemometer, and humicap data whose response time is greater than one second. These are respectively shown in (a), (b) and (c) of figure 22. 

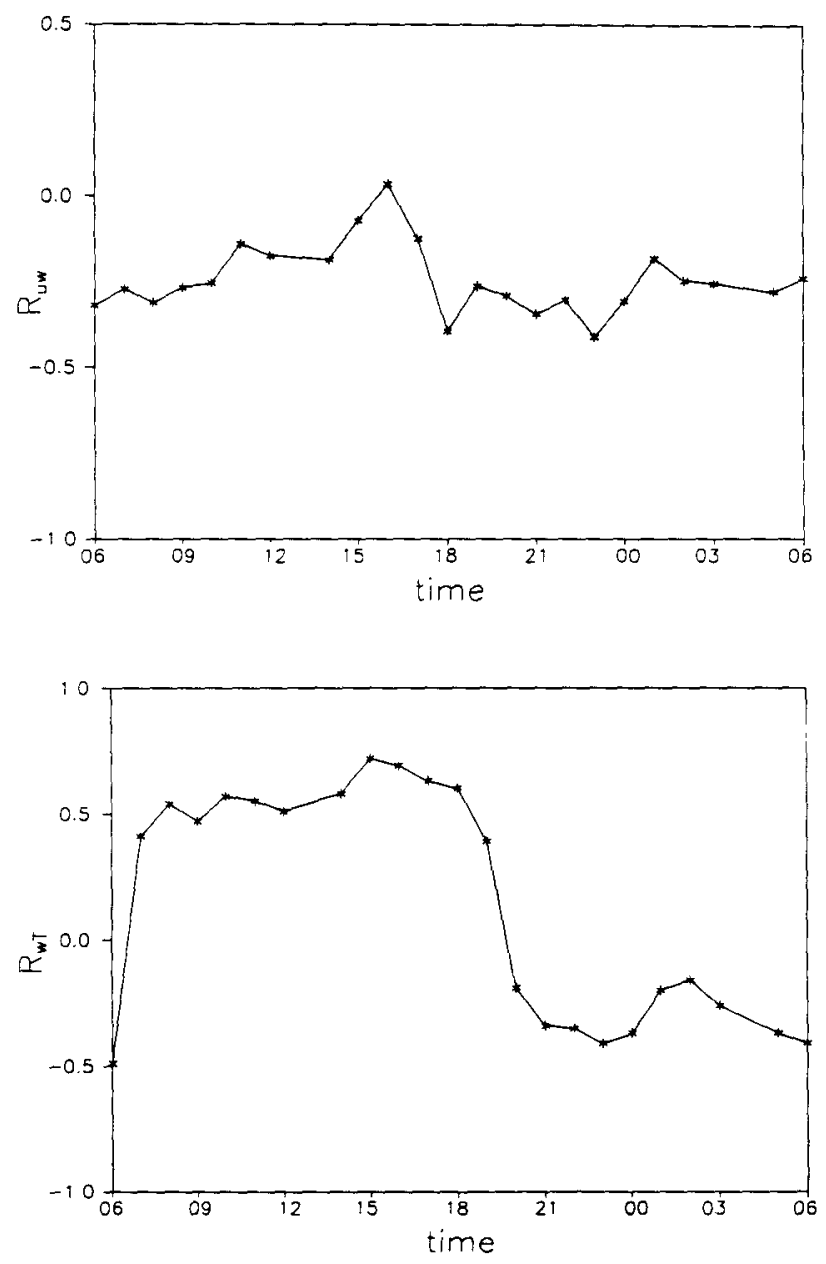

Figure 20. Diurnal variation of $\mathbf{R}_{w w}$ and $\mathbf{R}_{w T}$.

The line drawn in each figure gives the Kolmogorov slope of $-5 / 3$. Spectra of data from the faster response sonic anemometer (figure 22a, b) show the Kolmogorov slope at higher frequencies (up to $1 \mathrm{~Hz}$ and beyond). However, the spectra of data from the relatively slower sensor such as the humicap (figure 22c) show approximately the Kolmogorov slope below $1 \mathrm{~Hz}$, and deviate at higher frequencies (above $1 \mathrm{~Hz}$ ), presumably due to inadequate high frequency response and noise.

\section{Conclusions}

A typical tower instrumentation system which integrates both indigenous and imported sensors with an in-house data acquisition system has been described. The tower, the Campbell data logger, the PCM telemetry system and the PC/XT with the cartridge tape drive form the main basis of the instrumentation system. The 

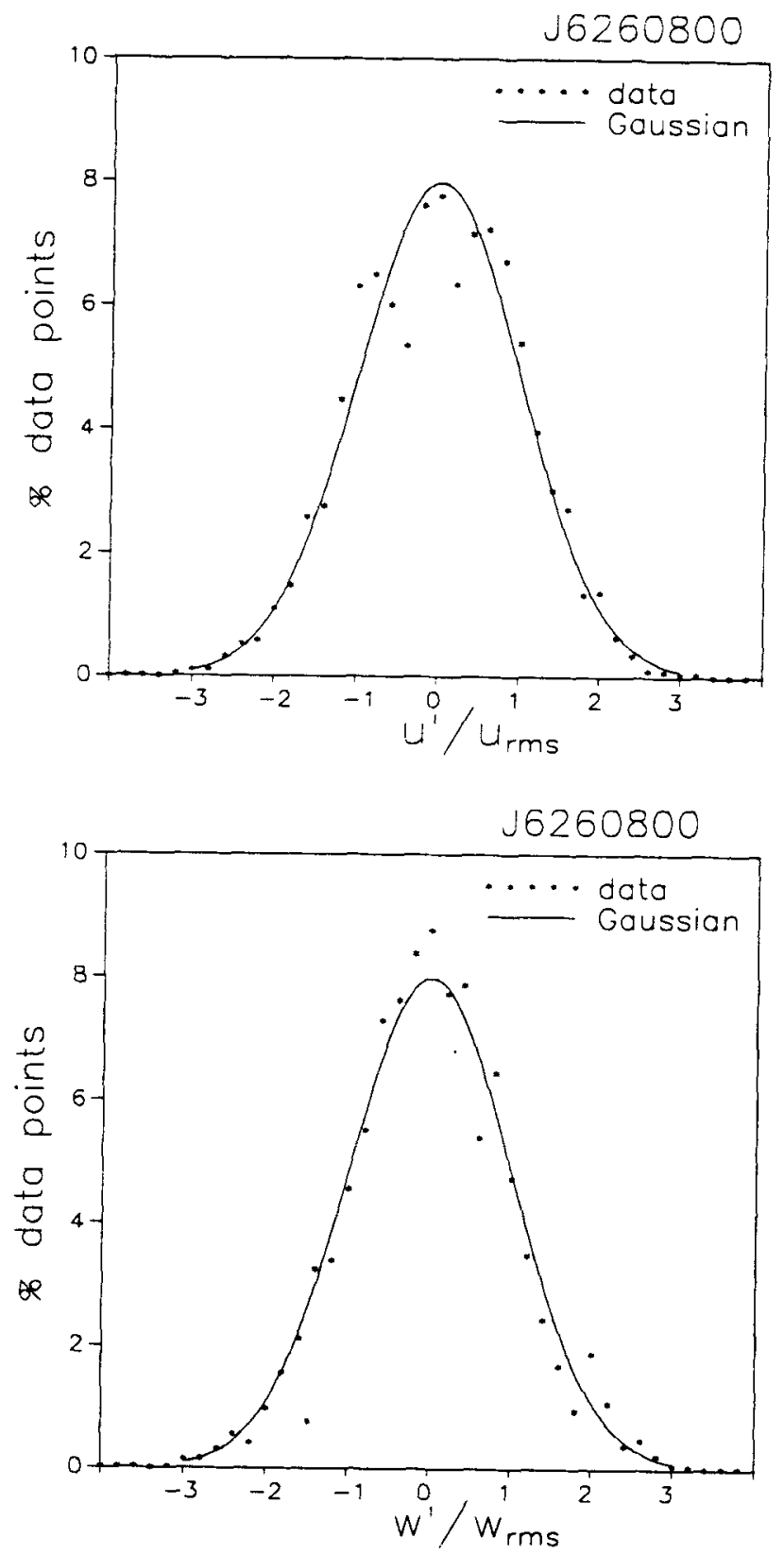

Figure 21. Distribution of $u$ and $w$ data from a sonic anemometer.

system has been configured in such a way that a large number of physical parameter sensors can be used in the experiment. The user-interactive software written on the PC as well as on the Campbell data logger enables the user to designate and identify the sensor and provides the option of entering the appropriate calibrations for these sensors. 

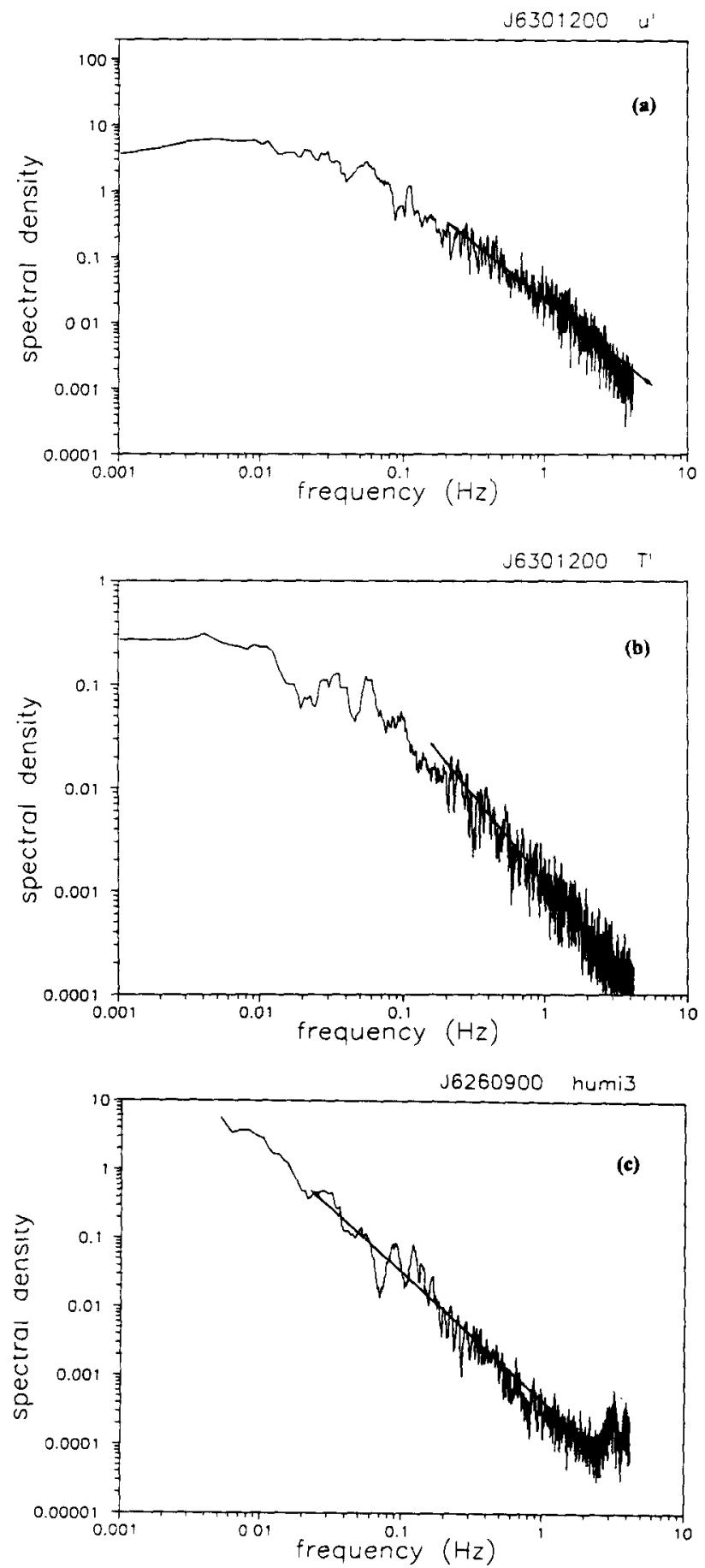

Figure 22. Power spectral density plot of (a) $u$ component and (b) $\mathrm{T}$ data from a sonic anemometer and (c) data from a humicap sensor. 
Tower observations carried out in the different convective zones of the monsoon trough during 1990 have resulted in the acquisition of a valuable set of atmospheric data under varied stability conditions. The instrumentation system, most of which was built indigenously (including the in-house built data acquisition system), functioned well in probing the atmospheric surface layer using $30 \mathrm{~m}$ tower platforms. The experience gained from this massive field experiment has been valuable. On the whole, observations at Jodhpur were the most successful in terms of number of good sets of continuous data.

A series of seven checks was made in order to verify the quality and validate the tower data from the field experiment carried out in the surface layer during MONTBLEX (1990). This quality analysis has established both qualitatively and quantitatively that the instrumentation system has recorded various physical variables in the surface layer quite accurately and has revealed the strong potential for further detailed analysis to understand the various aspects of boundary layer processes.

\section{Acknowledgements}

We thank all our colleagues at the Centre for Atmospheric Sciences, IISc for their excellent contributions during the observational programme. We thank all the scientists and technicians from other participant institutes who rendered help during the experiment. We also thank the host institutes for providing all the necessary support.

We thank Prof. $R$ Narasimha for his continuous encouragement and guidance throughout the experiment. We thank Dr Kusuma Rao, Dr Narahari Rao and Dr Kailas for their active participation and useful suggestions. We also thank Mr. H P Srinivasan for his contribution in the development of software programs for the data analysis.

\section{References}

Driedonks A G M, Van Dop M and Kohsiek W H 1978 Meteorological observations on the $213 \mathrm{~m}$ mast at Cabauw, in the Netherlands; Prepr. 4th AMS Symp. Meteor. Obs. Instr. (Denver) 41-46

Haugen D A, Kaimal J C and Bradley E F 1971 An experimental study of Reynolds stress and heat flux in the atmospheric surface layer; $Q . J . R$. Meteorol. Soc. 97 168-180

Kaimal J C and Gaynor J E 1983 Boulder Atmospheric Observatory; J. Appl. Meteorol. 22 863-880

Kaimal J C and Wyngaard J C 1990 The Kansas and Minnesota experiments; Boundary-Layer Meteorol. 50 $31-47$

Kaimal J C 1990 Basic tests for checking validity of field data. WPL Application note no. 5.

Narasimha R, Prabhu A, Rao K N, Adiga B S and Ameenulla S 1981 Project MOBLE-A monsoon boundary layer experiment at Balasore, July 1979. Report 81 FM 1. Department of Aerospace Engineering, IISc, Bangalore

Panofsky H A and Dutton J A 1984 Atmospheric turbulence (New York: Wiley Inter-Science Publications) Prabhu A, Rao K N, Kusuma G R, Kailas S V, Rudra Kumar S, Ameenulla S and Srinivasan H P 1990 The MONTBLEX pilot experiment. Report 90 AS 2; Centre for Atmospheric Sciences, IISc., Bangalore, India

Raman S, Templeman B, Templeman S, Murthy A B, Singh M P, Agarwal P, Nigam S, Ameenulla S and Prabhu A 1990 Structure of the Indian southwesterly pre-monsoon and monsoon boundary layer observations and numerical simulation; Atmos. Environ. A24 723-734

Rudra Kumar S, Sahu B R and Prabhu A 1990a The data acquisition software for the PC-based PCM telemetry system. Report 90 MD 4; Centre for Atmospheric Sciences, IISc, Bangalore, India

Rudra Kumar S, Srinivasan H P, Ameenulla S and Prabhu A 1990b PCM telemetry system. Report 90 MD 5; Centre for Atmospheric Sciences, IISc. Bangalore, India 
Rudra Kumar S, Srinivasan H P, Srikrishna R, Ameenulla S and Prabhu A 1991a Available tower data from MONTBLEX-90. Report 91 MD 1; Centre for Atmospheric Sciences, IISc, Bangalore, India.

Rudra Kumar S, Srinivasan H P, Satyadev H N, Ameenulla S and Prabhu A $1991 \mathrm{~b}$ Surface layer data from MONTBLEX-90. Report 91 MD 2; Centre for Atmospheric Sciences, IISc, Bangalore, India

Rudra Kumar S and Prabhu A 1991 Quality assessment of the tower data from MONTBLEX-90. Report 91 MD 3; Centre for Atmospheric Sciences, IISc, Bangalore, India 